\title{
Influence of Ambient Temperature on Nanosecond and Picosecond Laser-Induced Bulk Damage of Fused Silica
}

\author{
L. Yang, ${ }^{1,2}$ X. D. Yuan, ${ }^{1}$ H. X. Deng, ${ }^{2}$ X. Xiang, ${ }^{2}$ W. G. Zheng, ${ }^{1}$ S. B. He, ${ }^{1}$ \\ Y. Jiang, ${ }^{2}$ H. B. Lv, ${ }^{1}$ L. Ye, ${ }^{1}$ H. J. Wang, ${ }^{1}$ and X. T. $\mathrm{Zu}^{2}$ \\ ${ }^{1}$ Research Center of Laser Fusion, China Academy of Engineering Physics, Mianyang 621900, China \\ ${ }^{2}$ School of Physical Electronics, University of Electronic Science and Technology of China, Chengdu 610054, China
}

Correspondence should be addressed to X. D. Yuan; yxd66my@163.com

Received 28 February 2014; Accepted 3 June 2014; Published 19 June 2014

Academic Editor: Haiyan Xiao

Copyright (C) 2014 L. Yang et al. This is an open access article distributed under the Creative Commons Attribution License, which permits unrestricted use, distribution, and reproduction in any medium, provided the original work is properly cited.

\begin{abstract}
The nanosecond (ns) and picosecond (ps) pulsed laser-induced damage behaviors of fused silica under cryogenic and room temperature have been investigated. The laser-induced damage threshold (LIDT) and damage probability are used to understand the damage behavior at different ambient temperatures. The results show that the LIDTs for both ns and ps slightly increased at cryogenic temperature compared to that at room temperature. Meanwhile, the damage probability has an inverse trend; that is, the damage probability at low temperature is smaller than that at room temperature. A theoretical model based on heated crystal lattice is well consistent with the experimental results.
\end{abstract}

\section{Introduction}

Laser-induced damage of optics induced by the surface/ subsurface defects is a very important issue since the output power of laser systems is limited by the laser-induced damage threshold (LIDT) of optics. Therefore, much attention has been given to the surface damage of optics such as fused silica [1, 2], KDP crystals [3], and optical coatings [4]. As for the bulk damage of optics, the intrinsic damage and damage mechanism have been investigated [5-7]. The damage mechanism of long pulse is different from that of short pulse, the damage fluence departure from the long pulse diffusion-dominated $\tau^{1 / 2}$ scaling for $\tau<10$ ps $[8,9]$. Heated crystal lattice by laser that is relative to temperature is mainly responsible for the damage for long pulse [8]. However, the influence of ambient temperature $\left(T_{0}\right)$ on the laser-induced bulk damage in fused silica optics is little known for long pulse ( $>10$ ps) [10-13]. Merkle and Kitriotis [10] reported that both single and multiple pulse $(16 \mathrm{~ns}$ at $1064 \mathrm{~nm}, 10 \mathrm{~ns}$ at $532 \mathrm{~nm}$ ) damage differed very little between $80 \mathrm{~K}$ and $295 \mathrm{~K}$, and they compared the temperature dependence with several damage mechanisms, including multiphoton absorption, electron avalanche, inclusion heating, and bond breaking.
It seems that none of the damage models can explain all the phenomena of laser-induced damage in transparent materials adequately. Mikami et al. [11-13] studied the temperature dependence of LIDT in silica glass ( $4 \mathrm{~ns}$ at $1064 \mathrm{~nm}$ and $355 \mathrm{~nm}$ ) and its relationship with the concentration of impurities was discussed [11]. The results showed that the damage thresholds increased at low temperature. In addition, the temperature dependence became clearly dependent on the concentration of impurities at $1064 \mathrm{~nm}$. However, the temperature dependence of LIDT was almost the same for different concentrations of impurities at $355 \mathrm{~nm}$. The temperature dependence of nonlinear optical phenomena was also studied, indicating that both nonlinear refractive indices and stimulated Brillouin scattering (SBS) thresholds increased with decreasing temperature [12]. For the damage mechanism of longer pulses above a few picoseconds, Mikami et al. thought the initial temperature influences the generation of free-electron, electron avalanche, and critical density, which is responsible for the increased LIDTs at low temperature [14].

The laser-induced damage thresholds of optical coatings at different temperatures were also investigated [13]. The results showed that the damage thresholds of optical substrates and dielectric single-layer coatings increased linearly 
TABle 1: Output Specifications of the two laser devices.

\begin{tabular}{|c|c|c|c|c|c|c|}
\hline Laser devices & Wave length & Pulse duration & Max energy per pulse & Energy deviation & Waveform & Divergence angle \\
\hline \multirow{2}{*}{ Nd:YAG } & $1064 \mathrm{~nm}$ & $4-8 \mathrm{~ns}$ & $2300 \mathrm{~mJ}$ & \multirow{2}{*}{$<3 \%$} & \multirow{3}{*}{$\begin{array}{l}\text { Gaussian shape } \\
\text { with single } \\
\text { longitudinal mode }\end{array}$} & \multirow{3}{*}{$<0.5 \mathrm{mrad}$} \\
\hline & $355 \mathrm{~nm}$ & $6.3 \mathrm{~ns}$ & $520 \mathrm{~mJ}$ & & & \\
\hline Nd:YLF & $1053 \mathrm{~nm}$ & $50 \mathrm{fs}$ & $>50 \mathrm{~mJ}$ & $<1.5 \%$ & & \\
\hline
\end{tabular}
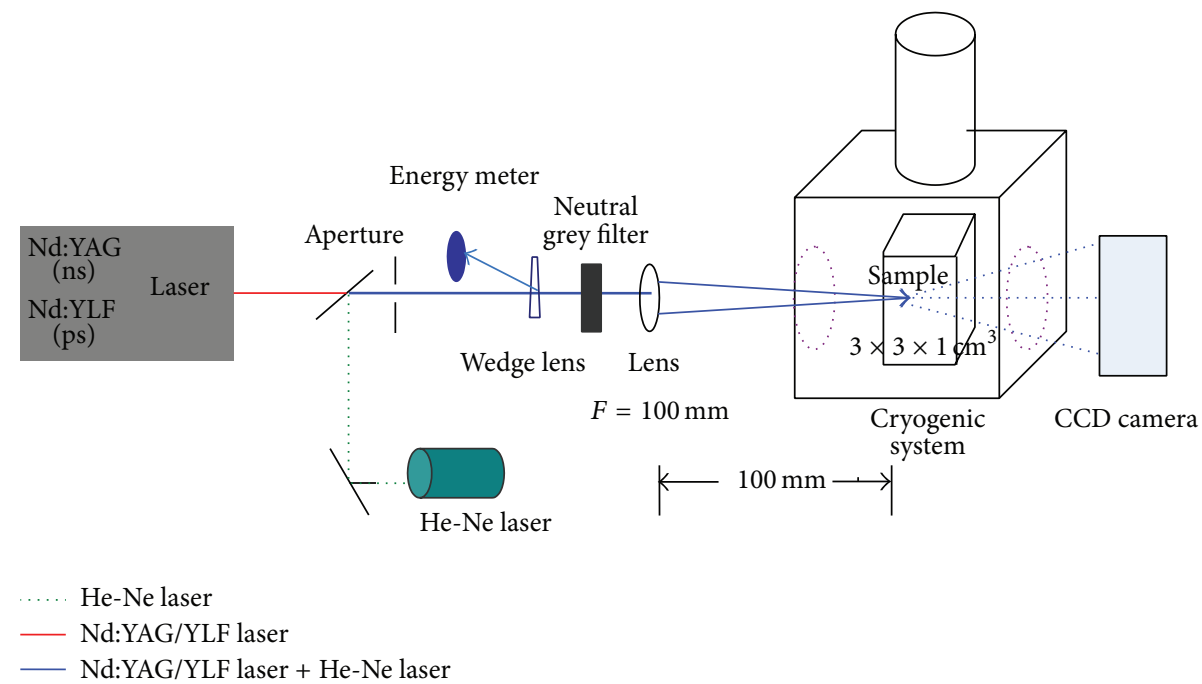

FIgURE 1: Experimental layout of LIDT measurement.

as the temperature decreased. However, Wang et al. investigated the laser-induced damage of antireflective coatings on Yb:YAG crystals under cryogenic condition and they concluded that the LIDT decreased at cryogenic conditions compared with room temperature. The subsurface defects in the substrate and the thermal stress at the interface between film and substrate under cryogenic conditions are considered to be the key factors for this damage behavior [15].

Therefore, it seems that there is no consistent experimental result about the relationship between temperature and LIDTs of optics. In addition, the underlying mechanisms about the influence of ambient temperature on the LIDT of optics have not been well understood. More experimental and theoretical works are still necessary to investigate the relationship between LIDT and ambient temperature.

In this work, the nanosecond (ns) and picosecond (ps) pulsed laser-induced damage thresholds and damage probability of fused silica under cryogenic and room temperature are investigated. A theory based on the influence of ambient temperature on the lattice temperature is presented to understand the LIDT of optics for long pulse.

\section{Material and Methods}

Optically polished fused silica glass sample (corning 7980) with dimensions of $30 \times 30 \times 10 \mathrm{~mm}^{3}$ was used in this work. Before experiments, the sample was etched firstly for about $10 \mathrm{~min}$ in a buffered $\mathrm{HF}$ solution $\left(1 \% \mathrm{HF}+15 \% \mathrm{NH}_{4} \mathrm{~F}+\right.$ $84 \% \mathrm{H}_{2} \mathrm{O}$ ) in order to remove the surface contaminations and blunt the surface scratch. Then the sample was cleaned immediately with pure water and alcohol after etching. The root mean square (RMS) of surface roughness measured by interferometer, after being etched by HF solution, is less than $0.5 \mathrm{~nm}$, which has little influence on the laser wave-front.

In this work, the influence of ambient temperature on LIDT of fused silica was studied by nanosecond and picosecond pulse. That is, the sample was irradiated by the fundamental (1064 nm) or third harmonic (355 nm) Nd:YAG laser and the fundamental $(1053 \mathrm{~nm}) \mathrm{Nd}$ :YLF laser in different ambient temperatures. The Output Specifications of the two devices are shown in Table 1. In order to obtain convincing comparison data, all conditions should be kept identical except for ambient temperature.

In order to calculate laser damage threshold, the diameter of the focal spots is measured. In this work, the diameter of the focused spot in fundamental frequency mode is about $130 \mu \mathrm{m}$ and in third harmonic mode is about $43 \mu \mathrm{m}$ for Nd:YAG laser. The diameter of the focused spot is about $19 \mu \mathrm{m}$ for the Nd:YLF laser.

Figure 1 shows the experimental layout. The incident laser pulse energy of Nd:YAG laser is adjusted by a half-wave plate and a dielectric polarizer integrated in the laser device. The energy of Nd:YLF laser is adjusted by changing the voltage value of the amplifier. The energy was monitored by an EPM1000 energy meter. After the laser pulse passes an appropriate aperture and a neutral grey filter, it is focused in the bulk of sample by a positive lens whose focal length is $100 \mathrm{~mm}$. In addition, a visible $\mathrm{He}-\mathrm{Ne}$ probe beam coaxial with the main laser beam is used for collimation to make sure that the area for study can be located accurately. The irradiated 


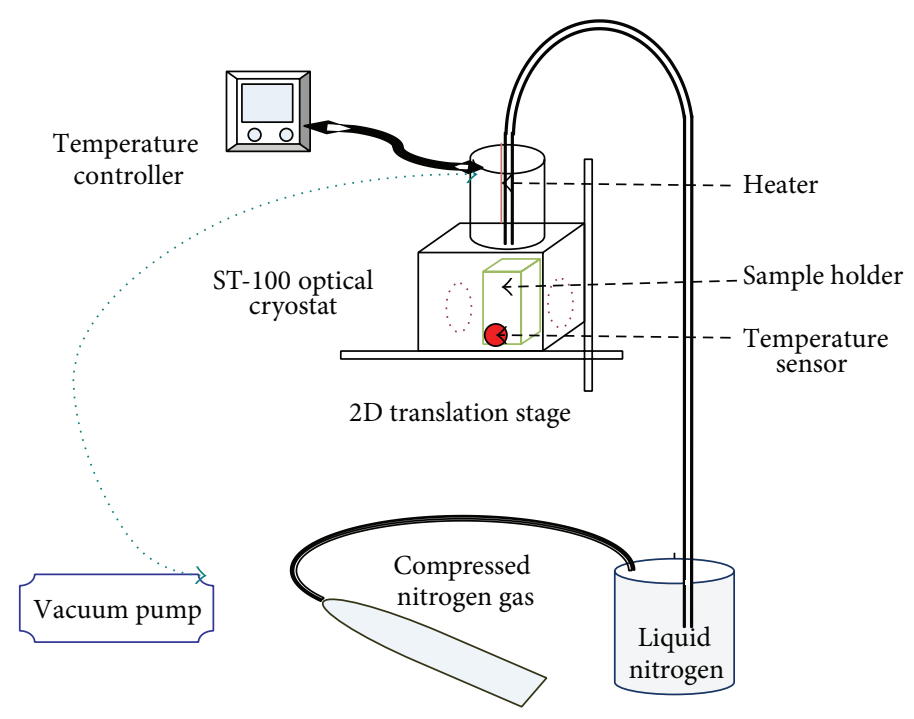

Figure 2: Cryogenic system.

zone by laser pulse is monitored and recorded by a long focal length CCD camera which was controlled by a computer.

Figure 2 shows the cryogenic system. The ST-100 optical cryostat is placed on the $2 \mathrm{D}$ translation stage in order to move the sample conveniently and accurately during experiments. The operation procedure of the cryogenic system is as follows. (1) The sample is mounted at the copper holder which is fixed in the liquid nitrogen optical cryostat; (2) the cryostat chamber is kept at $\sim 1.2$ Torr by using a molecular pump to prevent the water vapor in the atmosphere from condensing at low temperature; (3) the liquid nitrogen is introduced into the optical cryostat by the compressed nitrogen gas. In this way, we can control the temperature by adjusting the flow rate of fluid combined with a heater. The temperature is monitored by a sensor mounted on the sample holder, and the temperature is adjusted by the temperature controller connected with the sensor. The sample should be kept in the cryogenic chamber for 30 minutes before irradiation in order to assure that the sample has been cooled to the experimental temperature.

In this work, the LIDT and damage probability are tested at $1 \mathrm{~Hz}$ by "R-on-1" and "1-on-1" methods. For R-on-1 procedure, the same area was irradiated with a number of pulses at a repetition frequency with the increasing laser energy (increasing step $1 \mathrm{~J} / \mathrm{cm}^{2}$ from $10 \mathrm{~J} / \mathrm{cm}^{2}$ ) till the damage occurs. For "1-on-1" procedure, each site was irradiated with only one pulse, and 10 sites were tested at the same laser energy to obtain the damage probability. After that, repeat this process for next fluence.

In particular, the damage was detected by three methods: plasma emission, He-Ne laser scattering, and observation with CCD camera.

\section{Experimental Results and Discussion}

For the R-on-1 damage threshold test of samples, $A$ is defined as the maximum energy density before the component is damaged and $B$ is defined as the energy density when damage just occurs. Therefore, LIDT $=(A+B) / 2$ and its error bar is defined as error $=(B-A) / 2$, which includes both experimental equipment error and measuring error. In order to ensure the accuracy of LIDT, 10 sites are measured at each ambient temperature, so the mean value of the 10 sites is defined as average LIDT for this ambient temperature.

The laser-induced damage threshold and damage probability of fused silica tested at room temperature and cryogenic condition are given in Figure 3 to Figure 5.

Figure 3 shows the LIDT results (a) and damage probabilities (b) of fused silica at $80 \mathrm{~K}$ and $295 \mathrm{~K}$ for the Nd:YAG laser operated at $355 \mathrm{~nm}$. The average LIDT is $22.988 \mathrm{~J} / \mathrm{cm}^{2}$ at $295 \mathrm{~K}$ and $25.093 \mathrm{~J} / \mathrm{cm}^{2}$ at $80 \mathrm{~K}$ for 10 sites. This indicates that the LIDT increases about $9.16 \%$ and the damage probability decreases about 30\% under the liquid nitrogen cryogenic condition when irradiated by same laser pulse energy. A similar trend for $1064 \mathrm{~nm}$ is shown in Figure 4, where the average LIDT is about $24.83 \mathrm{~J} / \mathrm{cm}^{2}$ at $295 \mathrm{~K}$ and $26.807 \mathrm{~J} / \mathrm{cm}^{2}$ at $80 \mathrm{~K}$ for 10 sites. This indicates that the LIDT increases about $7.96 \%$ at $80 \mathrm{~K}$. Figure 5 shows that the LIDT results (a) and damage probabilities (b) of fused silica at $80 \mathrm{~K}$ and $295 \mathrm{~K}$ for the Nd:YLF laser operated at $1053 \mathrm{~nm}$. The average LIDT is $44 \mathrm{~J} / \mathrm{cm}^{2}$ at $295 \mathrm{~K}$ and $46.321 \mathrm{~J} / \mathrm{cm}^{2}$ at $80 \mathrm{~K}$ for 10 sites. The LIDT increases about $5.28 \%$ and the damage probability decreases a lot under the liquid nitrogen cryogenic condition.

The results in Figure 3 to Figure 5 exhibit a same trend; that is, the LIDTs of fused silica increase but the damage probability decreases under the liquid nitrogen cryogenic condition compared with room temperature, which is similar to the temperature dependences of laser-induced damage thresholds for silica glasses reported by Mikami and his coworkers [11].

\section{Theoretical Model and Discussion}

For the pulses longer than a few tens of picoseconds, Stuart et al. believed that the damage occurs via sufficient heat deposition on the lattice resulting in melting, boiling, or 


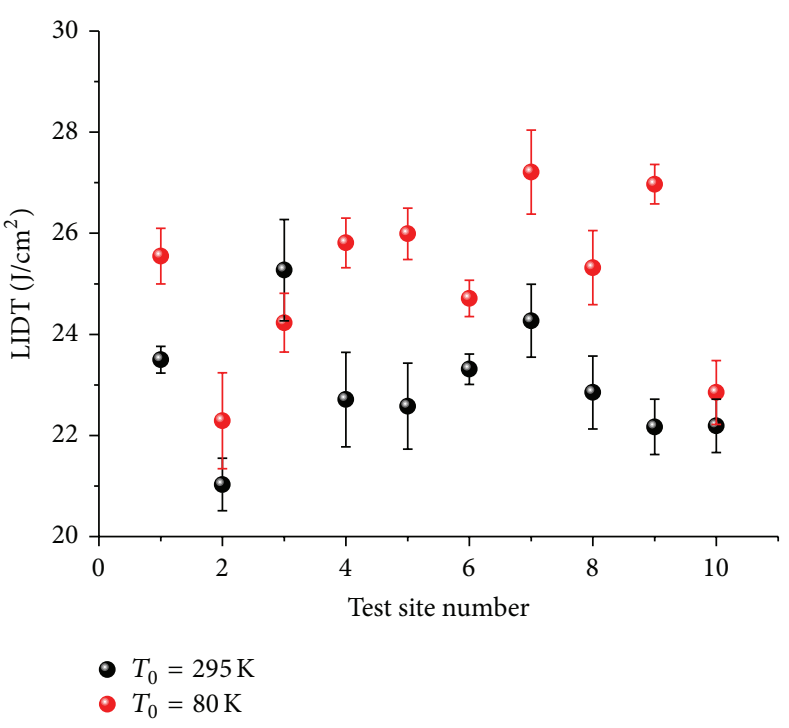

(a)

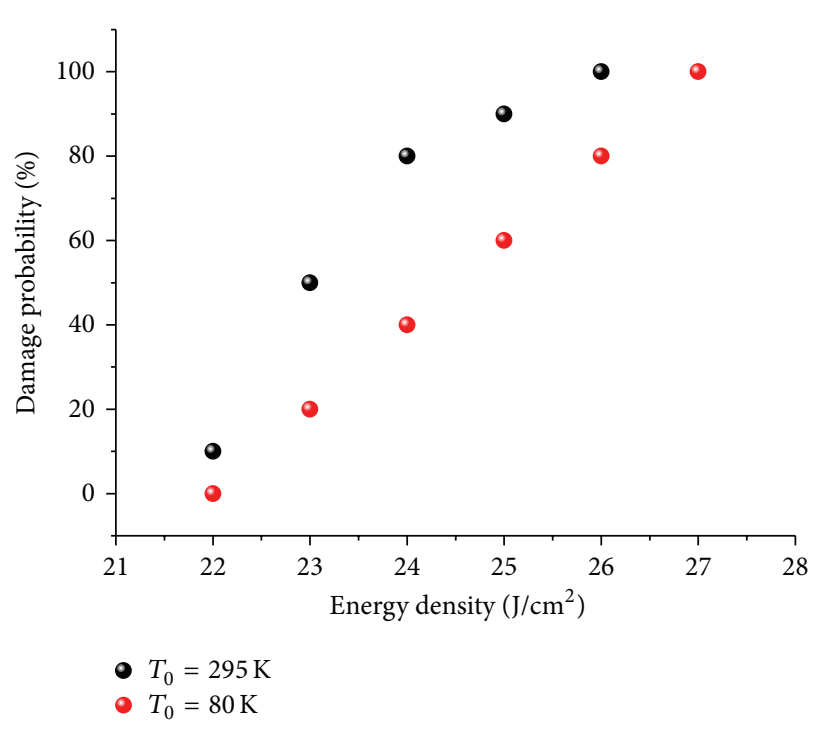

(b)

FIgURE 3: The LIDT (a) and damage probability (b) of fused silica at $80 \mathrm{~K}$ and $295 \mathrm{~K}$ tested by the ns Nd:YAG laser operated at $355 \mathrm{~nm}$.

fracturing the dielectric material because the laser pulse has sufficient time to transfer the energy to lattice $[8,9]$. It has been shown that pulse energy deposition on the lattice and its heating to the lattice to a critical temperature $\left(T_{C}\right)$ act the key roles during the damage process of several wide-gap materials including fused silica. When the damage occurs, melting or thermal stress damage may appear [16]. So we think the ambient temperature can influence the LIDT of optical components through affecting the lattice temperature.

For fused silica, at the location of $x, y, z$ in the Descartes coordinate, an arbitrary volume element can be defined as follows:

$$
d V=d x d y d z
$$

The relationship between the heat absorbed by the volume element and the temperature changing from $T_{0}$ to $T$ can be expressed as follows:

$$
d Q=C_{p}\left(T-T_{0}\right) d V,
$$

where $C_{p}$ is the heat capacity at points $x, y, z$, which is related to the material property and temperature. $T_{0}$ is the initial temperature of fused silica.

As most of the energy absorbed from laser contributes to raise the lattice temperature of fused silica and the irradiated time is $\tau$ (pulse width), we can get the formula

$$
d Q=\int_{0}^{\tau} I(x, y, z, t) \alpha d t d V
$$

where $\alpha$ is the absorption coefficient of fused silica, $I$ is the pulse power density at $x, y, z$. The power density is assumed in proportion to the incident laser power density $\left(I_{0}\right)$ before the material damages. Therefore,

$$
I \propto I_{0} .
$$

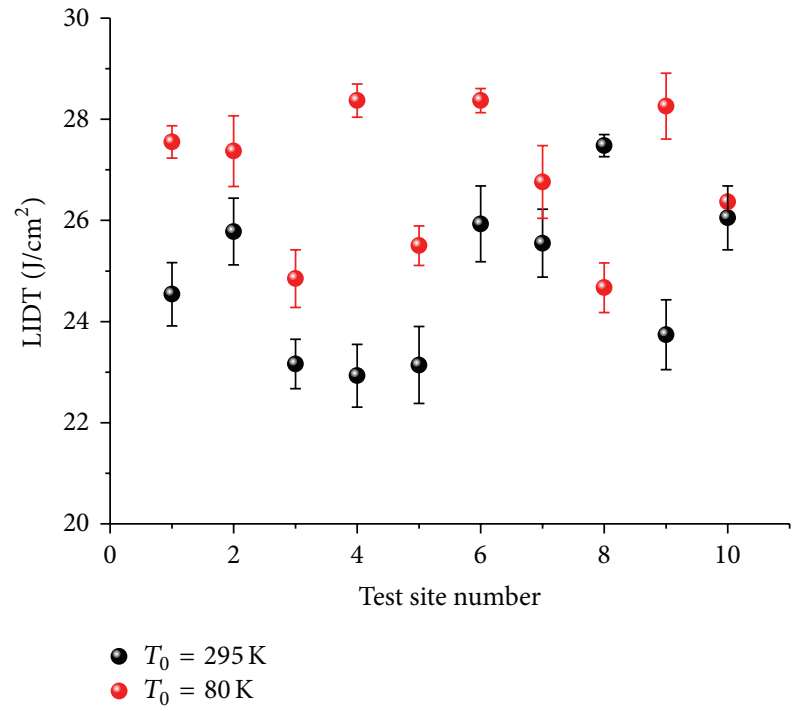

FIGURE 4: The LIDT of fused silica at $80 \mathrm{~K}$ and $295 \mathrm{~K}$ tested by the ns Nd:YAG laser operated at $1064 \mathrm{~nm}$.

Since the damage is dependent on the lattice temperature for long pulse, the critical temperature of the damaged site at $x, y, z$ is set to be $T_{C}$. According to Formula (2), the lattice needs to absorb the heat $C_{p}\left(T_{C}-T_{0}\right) d V$ to heat itself and its temperature rises from ambient temperature to critical temperature. Combined with Formula (3), we can get the following expression:

$$
\int_{0}^{\tau} I(x, y, z, t) d t^{\prime} d V=\frac{C_{p}\left(T_{C}-T_{0}\right)}{\alpha} .
$$




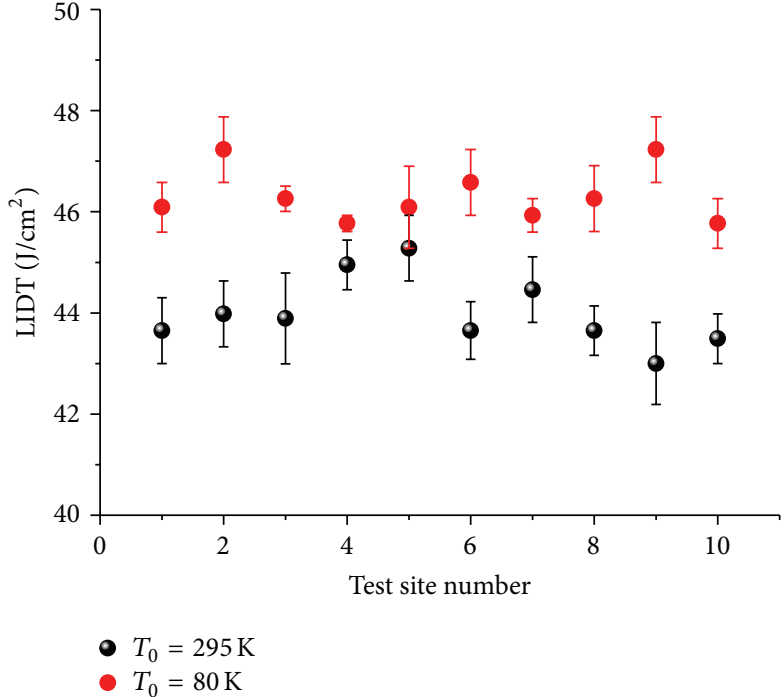

(a)

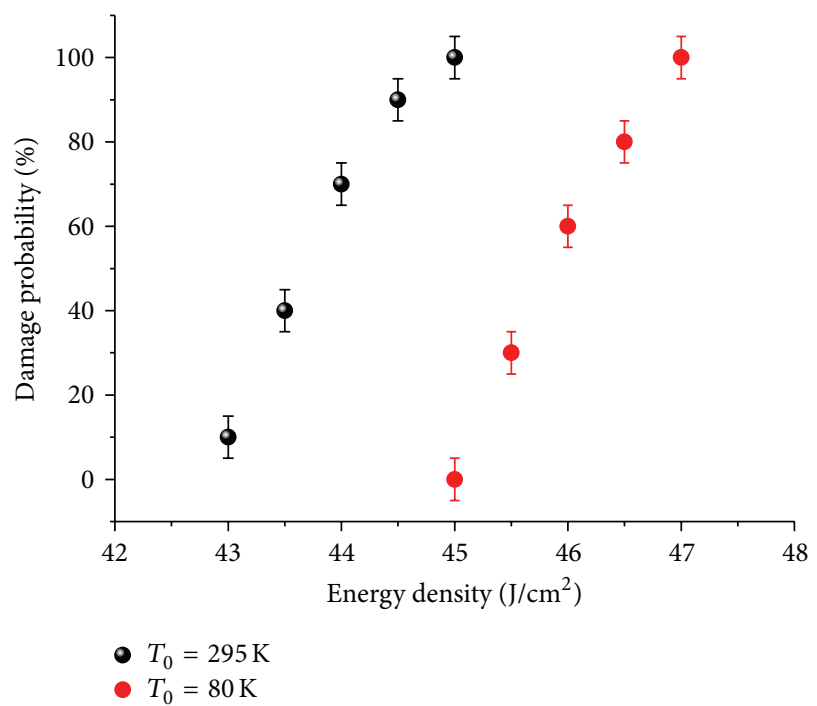

(b)

FIgURE 5: The LIDT (a) and damage probability (b) of fused silica at $80 \mathrm{~K}$ and $295 \mathrm{~K}$ tested by the Nd:YLF laser (ps) operated at $1053 \mathrm{~nm}$.

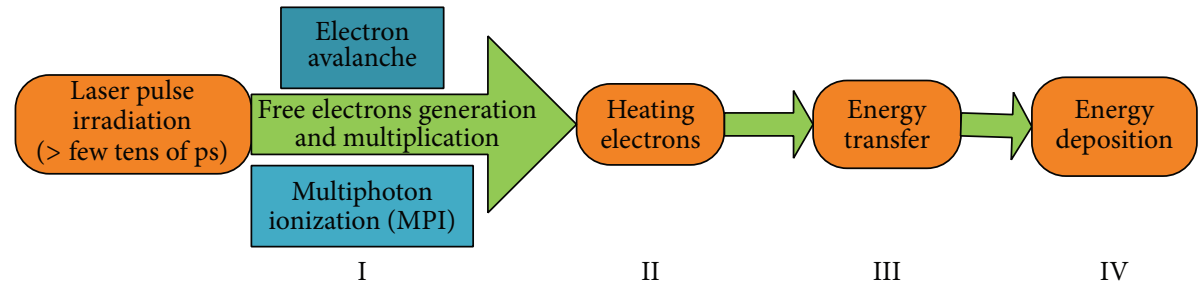

FIgURE 6: The processes of laser-induced dielectric material damage for the pulse longer than a few tens of picoseconds.

Combining formula (4) with (5), we can get the relationship between damage threshold with heat capacity, absorb coefficient, and temperature change as follows:

$$
E_{\text {th }} \propto \frac{C_{p}}{\alpha}\left(T_{C}-T_{0}\right) .
$$

Formula (6) can give an intuitive explanation. $C_{p}$ is the heat capacity which characterizes the temperature change after the material absorbs heat. For the larger heat capacity, the temperature of the material is more difficult to rise, so the heat capacity is proportional to the LIDT. $\alpha$ is the absorption coefficient of material, which characterizes the capacity to absorb laser energy, so it should be inversely proportional to the LIDT. $\left(T_{C}-T_{0}\right)$ characterizes the lattice temperature difference between initial temperature and critical temperature when it is irradiated by pulse laser. So the LIDT is linearly dependent on the temperature variation from Formula (6). As the heat capacity, absorb coefficient, and critical temperature are constant for one material, the LIDT of fused silica can be improved by decreasing the initial temperature.

The critical temperature which causes material damage is considered to be equal to the softening point temperature of fused silica. The softening point temperature of fused silica is about $1900 \mathrm{~K}$ [17], so $T_{C}=1900 \mathrm{~K}$. The damage threshold ratio of cryogenic temperature to room temperature is proportional to the temperature difference. Consider

$$
\frac{E_{\text {th }}(80 \mathrm{~K})}{E_{\mathrm{th}}(295 \mathrm{~K})} \propto \frac{T_{C}-80 \mathrm{~K}}{T_{C}-295 \mathrm{~K}} \approx 1.134 .
$$

In order to understand the temperature dependence, the processes of laser-induced dielectric material damage should be considered. According to the description by Stuart et al., the major damage processes for the pulse longer than a few tens of picoseconds concluded can be summarized as shown in Figure 6. The laser-induced damage involves four processes: (I) the excitation of electrons in the conduction band by electron avalanche and multiphoton ionization (MPI), (II) heating of the conduction-band electrons by the radiation, (III) transfer of the plasma energy to the lattice, and (IV) heating deposition result in the melting and boiling the material [8,9]. Merkle and Kitiotis [10] got the idea that the free electrons generated and multiplied by electron avalanche are the leading factor for the temperature dependence of laser-induced damage in dielectric material. Their model predicted that the LIDT at $80 \mathrm{~K}$ should be about 2.4 
times larger than that at $295 \mathrm{~K}$. However, their experimental results show that the damage threshold differed very little between $80 \mathrm{~K}$ and $295 \mathrm{~K}$. Mikami et al. [14] thought that the electron resistivity (i.e., electron mobility) is the key factor to elucidate the temperature dependence of laser-induced damage threshold. As the electrical resistivity of silica glass increases with decreasing temperature, the multiplication rate at low temperature is lower than that at room and high temperature. Thus laser-induced damage threshold increases at low temperature. The LIDT value decreased about 2 times from $473 \mathrm{~K}$ to $123 \mathrm{~K}$. However, their experimental results show that the LIDT just increases about $20 \%$ in $123 \mathrm{~K}$ compared to $473 \mathrm{~K}$. Therefore, the experimental results are much lower than the calculated results predicated by the two theoretical models.

In our theory model, we mainly consider the lattice heating. As energy deposition to lattice is related to the pulse duration, thermal conduction is in progress through the lattice during the interaction for long pulses [18]. Meanwhile, the heating deposition in the lattice causes the lattice temperature to rise. The critical temperature of fused silica is about $1900 \mathrm{~K}$, so it means that the fused silica will damage when the lattice temperature rises from $80 \mathrm{~K}$ to $1900 \mathrm{~K}$ rather than from $295 \mathrm{~K}$ to $1900 \mathrm{~K}$ under the liquid nitrogen condition. According to the relationship between LIDT and ambient temperature shown in formula (6), the lower the ambient temperature of lattice is, the higher the LIDT is. The calculated results show that the LIDT improves about 13.4\% at $80 \mathrm{~K}$ compared with $295 \mathrm{~K}$, indicating that the theoretical model based on heated crystal lattice is more approximate to the experimental data (9.16\%) compared with the previous models. In addition, when a high intensity pulse focused on an experimental sample in this study, some nonlinear optical phenomena (e.g., stimulated Raman scattering and self-focusing effect, etc.) may occur, which perhaps is another reason for temperature dependence of laser-induced damage thresholds [13].

\section{Conclusions}

The temperature dependence of laser-induced damage of fused silica is experimentally investigated. The LIDT increases about $9.16 \%, 7.96 \%$, and $5.28 \%$ from $80 \mathrm{~K}$ to $295 \mathrm{~K}$ for three different laser conditions. Meanwhile, the damage probability is lower at low temperature than room temperature for all conditions. The calculated result from the theory based on heated lattice is consistent with the experimental result.

\section{Conflict of Interests}

The authors declare that there is no conflict of interests regarding the publication of this paper.

\section{Acknowledgments}

This work is financially supported by the National Natural Science Foundation of China (Grant no. 61178018) and the
Ph.D. Funding Support Program of Education Ministry of China (Grant no. 20110185110007).

\section{References}

[1] N. Bloembergen, "Role of cracks, pores, and absorbing inclusions on laser induced damage threshold at surfaces of transparent dielectrics," Applied Optics, vol. 12, no. 4, pp. 661-664, 1973.

[2] J. Neauport, L. Lamaignere, H. Bercegol, F. Pilon, and J.C. Birolleau, "Polishing-induced contamination of fused silica optics and laser induced damage density at $351 \mathrm{~nm}$," Optics Express, vol. 13, no. 25, pp. 10163-10171, 2005.

[3] P. DeMange, R. A. Negres, H. B. Radousky, and S. G. Demos, "Laser-induced defect reactions governing damage performance in KDP and DKDP crystals," in Nonlinear Frequency Generation and Conversion: Materials, Devices, and Applications $V$, Proceedings of SPIE, January 2006.

[4] X.-Q. Chen, X.-T. Zu, W.-G. Zheng et al., "Experimental research of laser-induced damage mechanism of the sol-gel $\mathrm{SiO}_{2}$ and ibsd $\mathrm{SiO}_{2}$ thin films," Acta Physica Sinica, vol. 55, no. 3, pp. 1201-1206, 2006.

[5] S. C. Jones, P. Braunlich, R. T. Casper, X. A. Shen, and P. Kelly, "Recent progress on laser-induced modifications and intrinsic bulk damage of wide-gap optical materials," Optical Engineering, vol. 28, no. 10, pp. 39-67, 1989.

[6] H. X. Deng, X. Xiang, W. G. Zheng et al., "Theory of absorption rate of carriers in fused silica under intense laser irradiation," Journal of Applied Physics, vol. 108, no. 10, Article ID 103116, 2010.

[7] H. X. Deng, X. T. Zu, X. Xiang, and K. Sun, "Quantum theory for cold avalanche ionization in solids," Physical Review Letters, vol. 105, no. 11, Article ID 113603, 2010.

[8] B. C. Stuart, M. D. Feit, A. M. Rubenchik, B. W. Shore, and M. D. Perry, "Laser-induced damage in dielectrics with nanosecond to subpicosecond pulses," Physical Review Letters, vol. 74, no. 12, pp. 2248-2251, 1995.

[9] B. C. Stuart, M. D. Feit, S. Herman, A. M. Rubenchik, B. W. Shore, and M. D. Perry, "Nanosecond-to-femtosecond laserinduced breakdown in dielectrics," Physical Review B: Condensed Matter and Materials Physics, vol. 53, no. 4, pp. 1749-1761, 1996.

[10] L. D. Merkle and D. Kitriotis, "Temperature dependence of laser-induced bulk damage in $\mathrm{SiO}_{2}$ and borosilicate glass," Physical Review B, vol. 38, no. 2, pp. 1473-1482, 1988.

[11] K. Mikami, S. Motokoshi, M. Fujita, T. Jitsuno, J. Kawanaka, and R. Yasuhara, "Temperature dependence of laser-induced damage threshold in silica glass," Journal of Physics: Conference Series, vol. 244, no. 3, Article ID 032023, 2010.

[12] K. Mikami, S. Motokoshi, M. Fujita, T. Jitsuno, K. A. Tanaka, and H. Azechi, "Temperature dependence of laser-induced damage thresholds for dielectric and metal coatings," in Proceedings of the 2011 Conference on Lasers and Electro-Optics Europe and 12th European Quantum Electronics Conference, May 2011.

[13] K. Mikami, S. Motokoshi, M. Fujita, T. Jitsuno, and M. Murakami, "Temperature dependence of nonlinear optical phenomena in silica glasses," in Laser-Induced Damage in Optical Materials, vol. 7842 of Proceedings of SPIE, September 2010. 
[14] K. Mikami, S. Motokoshi, T. Somekawa, T. Jitsuno, M. Fujita, and K. A. Tanaka, "Laser-induced damage thresholds at different temperature for optical devices," in Pacific Rim Laser Damage 2013: Optical Materials for High Power Lasers, Proceedings of SPIE, May 2013.

[15] H. Wang, W. Zhang, and H. He, "Laser-induced damage behaviors of antireflective coatings at cryogenic condition," Applied Optics, vol. 51, no. 36, pp. 8687-8692, 2012.

[16] M. Frenz, G. Paltauf, and H. Schmidt-Kloiber, "Laser-generated cavitation in absorbing liquid induced by acoustic diffraction," Physical Review Letters, vol. 76, no. 19, pp. 3546-3549, 1996.

[17] M. Matthews, J. Stolken, R. Vignes et al., "Residual stress and damage-induced critical fracture on $\mathrm{CO}_{2}$ laser treated fused silica," in Laser-Induced Damage in Optical Materials, vol. 7504 of Proceedings of SPIE, 2009.

[18] M. H. Niemz, "Threshold dependence of laser-induced optical breakdown on pulse duration," Applied Physics Letters, vol. 66, no. 10, pp. 1181-1183, 1995. 

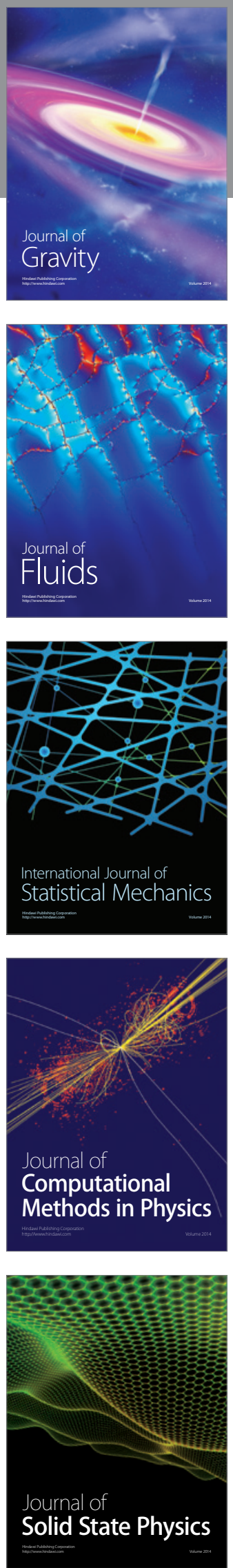

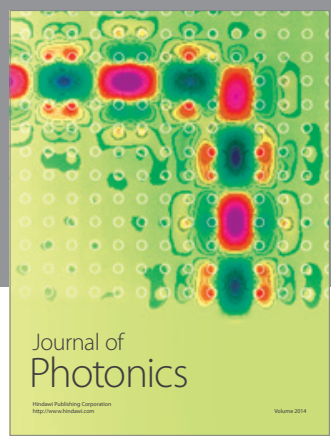

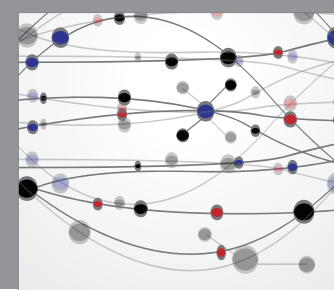

The Scientific World Journal

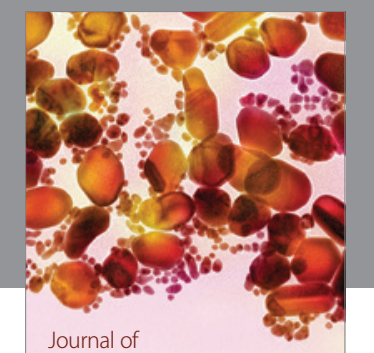

Soft Matter
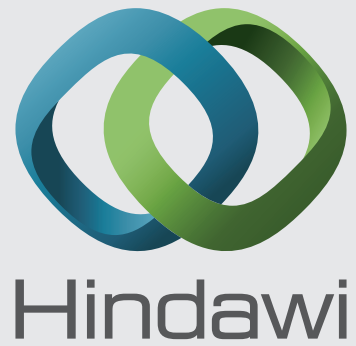

Submit your manuscripts at

http://www.hindawi.com
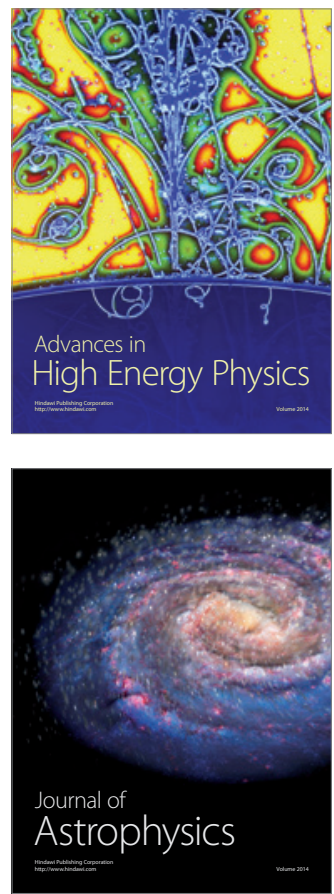
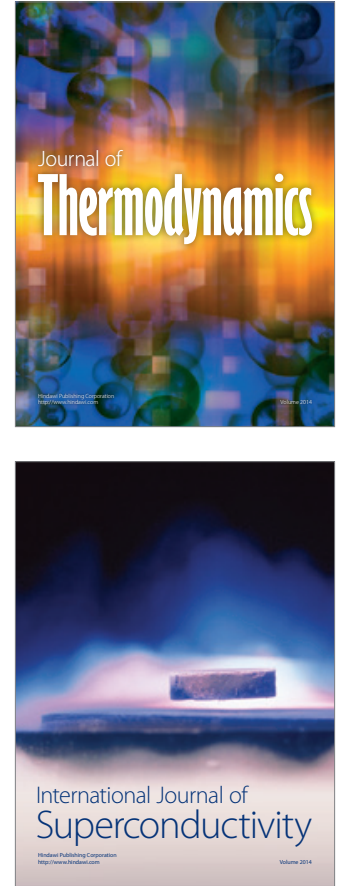
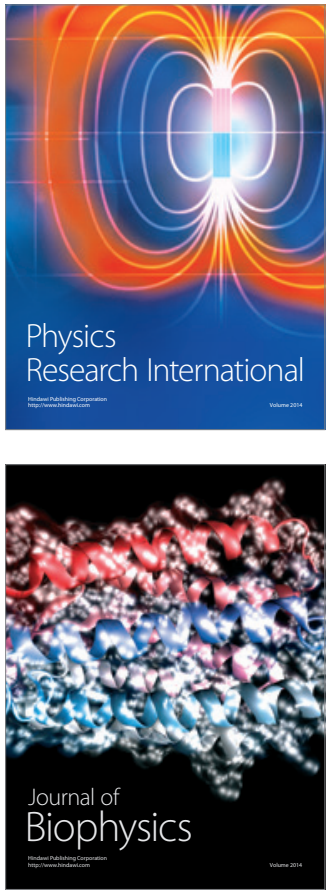
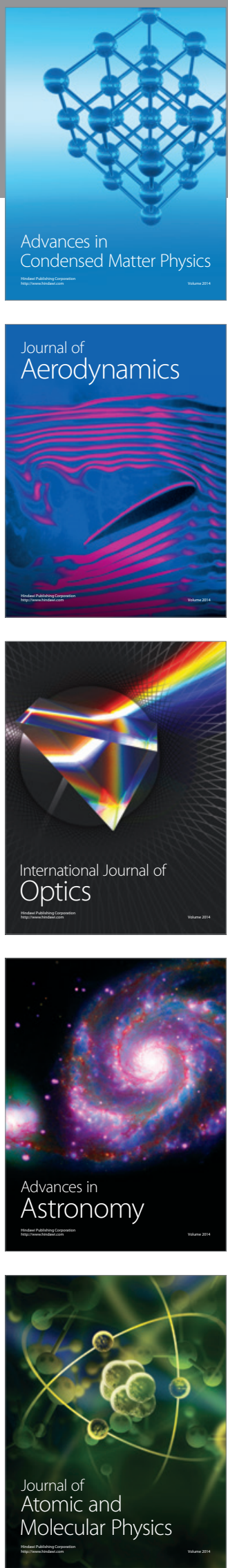